\section{Equity and inequity as a source of reward and punishment}

THOMAS L. RADINSKY, University of lowa, Iowa City, Iowa 52240

An experiment was performed to test the hypothesis, derived from equity theory, that equity and unfavorable inequity can act as a source of reward and punishment in addition to any reward provided by an individual's own outcomes. The results supported the hypothesis. It was also found that the choice behavior of females was more strongly influenced by equity and inequity than was that of nales.

A basic assumption in most general theories of human behavior is that people learn to make responses which are rewarded and not to make responses which are not rewarded or are punished. Moreover, if an individual's responses are rewarded with different reward magnitudes, he is expected to learn to make responses which result in larger rather than smaller rewards.

In recent years, considerable attention has been given to studying social interaction in the dyad with the experimental game paradigm (e.g., Gallo \& McClintock, 1965). In this paradigm, outcomes are usually indicated by numeric displays such that higher positive numbers correspond to higher rewards and higher negative numbers to lower rewards. In the experimental game paradigm, it is generally assumed that (a) the primary source of reward is the outcomes the individual receives, and (b) the reward value of these outcomes is linearly related to the numeric magnitude of the outcomes.

Due to the manner in which experimental games are typically studied, it can be argued that factors in addition to the outcomes themselves have reward value. In most experimental game studies, individuals are given complete information about the structure of the situation. This information is usually provided via a matrix of outcomes whose interpretation is carefully explained before individuals make any choices. From the matrix of outcomes it is possible for each person to see the possible outcomes for both himself and the other person, for all combinations of his own and the other person's choices. By means of the matrix of outcomes, an individual is able to compare his own outcomes with those of the other person. Such comparisons, hereafter referred to as interpersonal reward comparisons, may be a source of reward of considerable importance.

Equity theory, as developed by Homans (1961) and extended by Adams (1963, 1965), gives considerable emphasis to interpersonal reward comparisons as a source of influence on human behavior. According to these theorists, a person makes interpersonal reward comparisons and is thereby able to determine whether his outcomes are equitable or inequitable. Outcomes are equitable if a rule of distributive justice holds. The rule of distributive justice states that "a man in an exchange relation with another will expect the profits of each to be directly proportional to his investments [Homans, 1961, p. 244]." Profit is defined as reward less cost, and investments are defined as expectations of reward which reflect features of the background of the individual and the other person. Homans and Adams propose that men attempt to attain and maintain conditions of equity and to avoid conditions of inequity. In short, Homans and Adams hypothesize that equity is rewarding and inequity punishing.

Within the context of experimental game research, and in the present study, equity occurs when the chooser's and the other person's outcomes are equal, and inequity occurs when these outcomes are unequal. Equity is directly related to the outcomes of the two individuals for two reasons. First, dyad members are usually social peers, of the same sex, not previously acquainted, and drawn from a relatively homogeneous population (college students). The investments of any two such individuals can be assumed to be approximately equal. Second, since the task of the two individuals is the same, their costs are also equal. Under these conditions, equity and inequity depend only on the rewards of the two individuals, and the rewards depend only on the ou tcomes of the individuals.

The purpose of the present experiment was to demonstrate that equity and unfavorable inequity can serve as sources of reward and punishment in a simple two-choice situation. Two conditions are necessary to make this demonstration. One condition is that an individual be exposed only to his own and the other person's outcomes. In experimental game research, the matrix of outcomes gives the individual information about which choices the other person made, as well as about the other person's outcomes. If an individual is exposed to the other person's choices, factors in addition to interpersonal reward comparisons, such as imitation and influence attempts, may also play a role in determining the chooser's selections. In the present study, individuals were neither shown an outcome matrix nor in any other way given information about the other person's choices.

The second condition is that there be a control condition which differs from the experimental condition in that no opportunity is available for making interpersonal reward comparisons. In both conditions, there must be the same response contingencies with respect to the chooser's own outcomes. In the present study, individuals in the experimental condition were given feedback consisting of displays of both their own and the other person's outcomes (the both-display condition). Interpersonal reward comparisons could easily be made by these individuals. In the control condition, the feedback consisted of a display of only the chooser's own outcomes (the owndisplay condition). For these individuals, the possibility of making interpersonal reward comparisons was experimentally eliminated. Although the individuals were told that they were interacting with one another to determine their outcomes, the probabilities of occurrence of the outcomes and their contingencies to the individuals' choices were controlled by the $E$. This control was needed so that individuals in both experimental and control conditions would be exposed to the same response contingencies with respect to the chooser's own outcomes.

In the present study, equity and unfavorable inequity were made contingent on an individual's choices. Specifically, in the both-display condition, one choice (A l) consistently resulted in equity and the other choice (A2) had a high probability of occurrence of unfavorable inequity ${ }^{1}$ and a low probability of occurrence of equity. In the own-display condition, individuals were not exposed either to equity or unfavorable inequity. But the both-display and owndisplay conditions were comparable in all other respects. If the chooser's own outcomes are the primary source of reward, and if equity and inequity do not act as sources of reward and punishment, then there should be no difference in the choice behavior of individuals in the experimental and control conditions.

However, if equity is rewarding and unfavorable inequity punishing, then with respect to equity and unfavorable inequity, the Al choice is consistently rewarded and the A2 choice is frequently punished with unfavorable inequity and infrequently rewarded with equity. Since equity and unfavorable inequity are not present as a source of reward and punishment in the own-display condition, equity theory leads to the prediction that individuals in the both-display condition will make fewer A2 choices than individuals in the own-display condition.

A secondary objective of the present experiment was to determine if an outcome 
greater than any other of the chooser's possible outcomes would be rewarding disproportionately to its probability of occurrence. This objective was accomplished by arranging the situation so that the A2 choice had a low probability of occurrence of a high outcome and a high probability of occurrence of a low ou tcome. With the Al choice, the chooser always received one of two intermediate outcomes, i.e., outcomes larger than the low outcome but smaller than the high outcome. For all individuals, the probabilities of occurrence of the outcomes were such that the total accumulation of points over all trials was approximately ${ }^{2}$ the same, irrespective of whether the A1 or A2 choice was consistently made. It was expected that if individuals in the own-display group find the high outcome disproportionately rewarding, then they should learn to make the $A 2$ choice more often than the Al choice.

Both male and female dyads were used in the present study. Neither Homans nor Adams makes any general statements about differential sensitivity of males and females to equity or unfavorable inequity. In addition, results using experimental games are inconsistent (cf. Radinsky, in press; Rapoport \& Chammah, 1965). Hence, no predictions with regard to sex were made in the present study.

\section{PROCEDURE}

The Ss were 64 students ( 32 male and 32 female) from introductory psychology courses who chose to participate in experiments in order to fulfill course obligations. They were requested not to sign up for the same experimental session as a friend, and they participated in the experiment in pairs of the same sex.

The Ss were seated in separate rooms and given tape recorded instructions. A written copy of the instructions was available to the Ss. The Ss were told that their joint choices determined the outcomes they received. The stated objective was for each person to accumulate as many points as he could. These points had no monetary value. Before beginning the experimental session, the $E$ checked with each $S$ to see if he had any questions. If there were any questions, the appropriate parts of the instructions were paraphrased.

Each $S$ had before him two choice buttons and a vertical panel. Near the top of the vertical panel was a green pilot light labelled "cloose." When the "choose" light came on, the $S$ was to select and press one of the two buttons.

Directly below the "choose" light there was a digital display labelled "Your Points." Below this was a second digital display, this one labelled "Other's Points." Both displays could indicate any one or two digit numbers. Individuals in both-display groups were

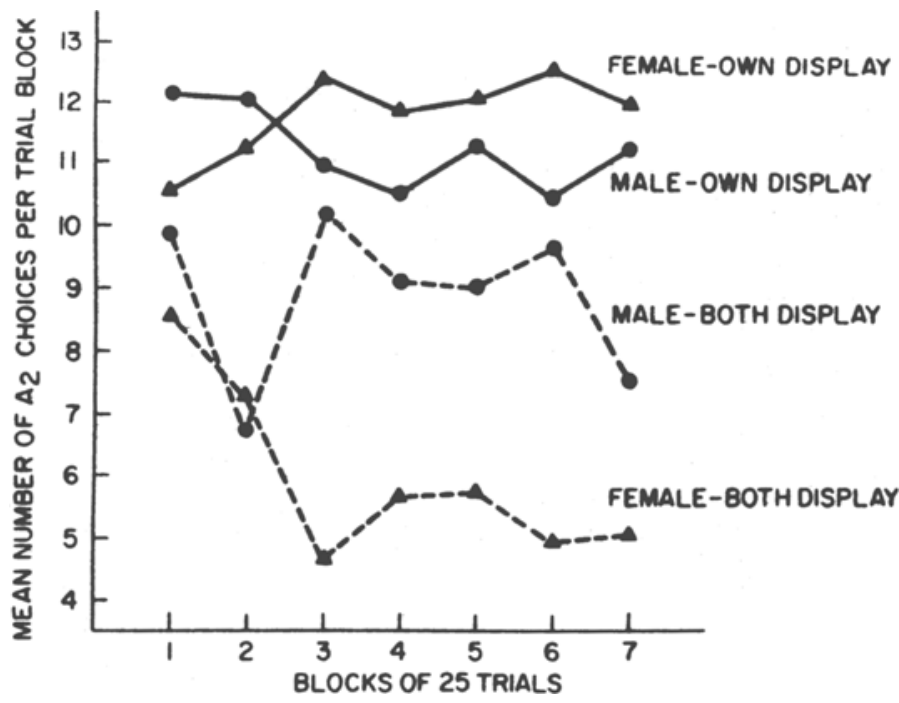

Fig. 1. Mean number of $A 2$ choices per trial block as a function of sex and display.

exposed to both of these displays. For individuals in own-display groups, the display labelled "Other's Points" was concealed.

After both Ss had responded, the digital displays were illuminated for $3 \mathrm{sec}$. During this time, the Ss recorded their outcomes on a sheet provided for this purpose. There were a total of 175 trials.

\section{OUTCOMES AND \\ OUTCOME PROBABILITIES}

For the A2 choice, the chooser's outcomes were either 15 or 4 points. Fifteen points occurred with a probability of .30 and 4 points with a probability of $70 .^{3}$ For the Al choice, the chooser's outcomes were 8 and 6 points, which occurred with probabilities of .65 and .35 , respectively. In the both-display groups, all outcomes were indicated as equal for the chooser and the other person, except with the 4 . When the 4 appeared, the other person was always indicated as receiving 9 points.

$$
\text { APPARATUS }
$$

The number of points which a $S$ received depended on his choice and that state of a relay which the $E$ controlled. The $E$ manipulated the relays independen tly of the Ss' choices, and all Ss were exposed to the same random sequence of probabilities of the relays being in the resting or closed states. The probabilities were subject to the constraint that the stated values occur within each block of 20 trials.

A paper tape punch was used to record the $\mathrm{Ss}$ responses and information about the sequence of outcomes each $S$ received. Standard electrical equipment was used to properly time the display intervals and operate the tape punch. The equipment was designed so that the function of the $\mathrm{Ss}^{\prime}$ pushbuttons could be reversed. Half the Ss were randomly assigned to either the reversed or nonreversed states. The manipulation provided a control for position preferences.

The hypothesis that individuals would make fewer A2 choices in the both-display than in the own-display conditions was supported $(F=25.42, \mathrm{df}=1 / 60, \mathrm{p}<.001)$. In an analysis of variance performed on the number of $A 2$ choices in each of seven trial blocks for each $S$, with between factors of sex and display (both and own), and a within factor of trial blocks, the three factors were found to interact $(F=2.82, \mathrm{df}=6 / 630$, $p<.05)$. The nature of this interaction is shown in Fig. 1. Both males and females made fewer A2 choices in the both-display than own-display conditions, but females did so to a greater extent than males. In addition, individuals in the both-display conditions (but especially females) made a decreasing number of $A 2$ choices over trial blocks, but those in the own-display conditions made about the same mean number of $A 2$ choices in all trial blocks.

The hypothesis that individuals in the own-display condition would find the high outcome disproportionately rewarding was not supported. In fact, there was a tendency for individuals to make more A1 than A2 choices, which is the reverse of what was predicted. DISCUSSION

The results of the present experiment appear to give strong support to the hypothesis that equity and unfavorable inequity can serve as a source of reward and punishment in a simple two-choice situation. Moreover, it appears that females are more likely than males to come to prefer a choice wisich assures equity to one which has either a high probability of occurrence of unfavorable inequity or a low probability of occurrence of equity. 
With respect to experimental games, it appears that the assumption that the primary source of reward is the individual's own outcomes is not necessarily true. As the present experiment shows, interpersonal reward comparisons may also serve as sources of reward. In analyzing the experimental game situation, it is clearly necessary to take into account interpersonal reward comparisons (e.g., Messick \& McClintock, 1968).

Since it appears that equity and unfavorable inequity can act as rewards in a two-choice situation, research is currently in progress to explore these effects on choice behavior more thoroughly, and to also examine the reward value of favorable inequity.

\section{REFERENCES}

ADAMS, J. S. Toward an understanding of inequity. Journal of Abnormal \& Social Psychology, 1963, 67, 422-436.

ADAMS, J. S. Inequity in social exchange. In L. Berkowitz (Ed.), Advances in experimental social psychology. Vol. 2. New York: Academic Press, 1965. Pp. 267-299.

Gallo, P. S., JR., \& MaClinTOCK, C. G. Cooperative and competitive behavior in mixed-motive games. Journal of Conflict Resolution, 1965, 9, 68-78.

HOMANS, C. G. Social behavior: Its elementary forms. New York: Harcourt, Brace, 1961.

MESSICK, D. M., \& MCCLINTOCK, C. G. Motivational bases of choice in experimental games. Journal of Experimental Social Psy chology, 1968, 4, 1.25.

MESSICK, D. M., \& THORNGATE, W. B. Relative gain maximization in experimental games. Journal of Experimental Social Psychology. 1967, 3, 85-101.

RADINSKY, T. L. Relative loss avoidance in the triple dominance game. Psychology, in press.

RAPOPORT, A., \& CHAMMAH, A. Sex differences in factors contributing to the level of cooperation in the Prisoner's Dilemma game. Journal of Personality \& Social Psychology, $1965,2,831-838$

\section{NOTES}

1. It should be noted that in the present experiment unfavorable inequity was consistently paired with a low outcome. This combination frequently occurs in experimental games. In addition, Messick \& Thorngate (1967) have shown that the combination of a low outcome and unfavorable inequity is a major source of influence on the pattern of interaction of individuals in a dyadic relation.

2. Actually, for half the Ss, the total accumulation of points over all trials was about $15 \%$ greater for the A2 than A1 choice. However, preliminary analysis indicated that this factor was not significant and did not interact with any other factor. Therefore, no further attention was given to this factor. Individuals are apparently not sensitive, in the present situation, to a difference as small as $15 \%$.

3. In the case of those Ss for whom the total point accumulation was $15 \%$ greater for the A2 than Al choice, the probabilities of occurrence of the 15 was .40 and that of the 4 was .60 . No changes were made with the probabilities of occurrence of the 8 and 6 . See Note 2 .

\section{Effects of signaled time-out from and loss of monetary reinforcement on human operant behavior'}

IRENE A. TRENHOLME, ALAN BARON, and ARNOLD KAUFMAN, University of Wisconsin-Milwaukee, Milwaukee, Wis. 53201

A signal followed by a period of time-out from reinforcement was presented while human $S$ s were responding to procure monetary reinforcement on a variableinterval schedule. The results replicated previous findings with animals of response facilitation in the presence of the signal. Facilitation also was observed when the signal preceded a brief stimulus indicating that money had been lost. The results were consistent with the hypothesis that response facilitation reflects conditioning of frustration to the signal. But it also was observed that in the majority of cases increased responding resulted in increased rates of reinforcement, thus suggesting that increased reinforcement may have been a factor in producing rate increases.

Ferster (1958) and Leitenberg (1966) used chimpanzees and pigeons to study reactions to stimuli signaling time-out from positive reinforcement. Their procedures involved pretraining on variable-interval (VI) schedules of food reinforcement and discrimination of interposed time-out periods when reinforcement was unavailable. When the time-out periods then were preceded by a signal, the characteristic reaction was heightened responding in the presence of the signal.

The present study was designed to investigate human reactions to analagous procedures. In comparison to the studies cited above, money served as the positive reinforcer, loss of positive reinforcement already gained as well as time-out was studied, and discrimination of the time-out and loss events was established through instructions.

\section{SUBJECTS AND APPARATUS}

Eight young adult college students were paid for a series of 50 -min sessions on the basis of their performance in the experimental situation. Information about the amount earned was given after each session, but actual payment occurred only at the end of the experiment. Ss sat at a table in a $6-\mathrm{ft} \mathrm{sq}$ sound-attenuated room. Located on the table was a sloping panel containing three ground-glass screens and a plastic pushbutton.

\section{INSTRUCTIONS}

Printed instructions which were in the room throughout the experiment indicated that: (a) brief green illumination of the left screen signified that 5 cents had been earned;(b) the green light would sometimes go on when the button was pressed; (c) blue illumination the center screen would serve as a signal; (d) continuous yellow illumination on the right screen signified 